PSI COLOGI A SOCI AL

\title{
Vamos ser inclusivos/as? Campanhas na mídia e produção de verdades sobre inclusão
}

\section{Shall we be inclusive? Media campaigns and production of truths about inclusion}

\section{¿Vamos a ser inclusivos/as? Campañas en los medios de comunicación y producción de verdades sobre inclusión}

\author{
Betina Hillesheim* \\ Universidade de Santa Cruz do Sul - UNISC, Santa Cruz do Sul, Rio Grande do Sul, \\ Brasil
}

\section{Amanda Cappellari**}

Universidade Federal do Rio Grande do Sul - UFRGS, Porto Alegre, Rio Grande do Sul, Brasil

\begin{abstract}
RESUMO
Este artigo propõe-se a discutir o que pode ser denominado como incitação à inclusão, mediante campanhas veiculadas na mídia impressa. Considerandose que a mídia exerce uma função importante na produção e difusão de discursos, discutem-se as campanhas como estratégias que visam educar para a inclusão, argumentando como essas nos constituem como sujeitos inclusivos/as. Além disso, busca-se compreender de que forma os discursos da Psicologia se entrelaçam à produção de verdades sobre inclusão. Para tanto, foram selecionadas 23 reportagens sobre campanhas inclusivas, através da análise das edições do jornal Zero Hora, no período de março a dezembro de 2015. Para analisar as campanhas, as mesmas foram agrupadas em tabelas que visibilizam quem são os sujeitos da inclusão, quais as estratégias e ações inclusivas, e quais as justificativas para tais campanhas. Problematiza-se como as campanhas inclusivas se constituem como estratégias educativas, que ampliam a inclusão dos mais variados sujeitos, subjetivando a todos através do imperativo da inclusão. Aponta-se, ainda, que a ideia de inclusão é composta por diferentes vetores, tanto no sentido de normalização, quanto de multiplicação da diferença.
\end{abstract}

Palavras-chave: inclusão, mídia, diferença, campanhas, discurso.

\begin{abstract}
This paper aims to discuss what can be named as incitation to inclusion through campaigns disseminated in print media. Considering that media plays an important role in the production and propagation of discourses, this paper approaches the campaigns as strategies which aim to educate for inclusion, arguing how them constitute us as inclusive subjects. In addition, it is sought to understand in what way the discourses of Psychology are intertwined with the production of truths about inclusion. In order to do that, 23 reports about inclusive campaigns were selected from Zero Hora
\end{abstract}


newspaper, from March to December 2015. To analyze the campaigns, they were grouped in tables that emphasize who are the subjects of inclusion, which are the inclusion strategies and actions and which are the justifications for such campaigns. It is problematized how the inclusive campaigns have been constituted as educative strategies that widen the inclusion of several subjects, thus subjectifying everyone by means of the inclusion imperative. It is also pointed out that the idea of inclusion is composed of different vectors, both in the sense of normalization and multiplication of difference.

Keywords: inclusion, media, difference, campaigns, discourse.

\section{RESUMEN}

Este artículo se propone a discutir lo que puede ser nombrado como incentivo a la inclusión, a través de campañas transmitidas en los medios impresos. Considerándose que los medios de comunicación ejercen una función importante en la producción y difusión de discursos, se discuten las campañas como estrategias que objetivan educar para la inclusión y se argumenta como ésas nos constituyen como sujetos inclusivos(as). Además, se busca comprender de qué forma los discursos de la Psicología se entrelazan a la producción de verdades sobre inclusión. Para ello, se han seleccionado 23 reportajes sobre campañas inclusivas, a través del análisis de las ediciones del periódico Zero Hora, en el período de marzo a diciembre de 2015. Para analizar las campañas, ellas fueron agrupadas en tablas que visibilizan a quienes son los sujetos de la inclusión, cuáles son las estrategias y las acciones inclusivas, y cuáles son las justificaciones para tales campañas. Problematiza cómo las campañas inclusivas se constituyen como estrategias educativas, que amplían la inclusión de los más variados sujetos, subjetivando a todos a través del imperativo de la inclusión. Se apunta, además, que la idea de inclusión está compuesta por diferentes vectores, tanto en el sentido de normalización, como de multiplicación de la diferencia.

Palabras clave: inclusión, medios de comunicación, diferencia, campañas, discurso.

Os(as) psicólogos(as) têm sido demandados(as) no sentido de dar conta de diversas situações relacionadas à inclusão: no campo das políticas públicas (marcado pela ideia de acesso a todos), nas questões referentes às pessoas com deficiência ou com diagnósticos psiquiátricos, em resposta a discriminações e desigualdades de diversas ordens (sexuais, de gênero, sociais, religiosas, etc.), etc. Entretanto, ainda não percebemos uma suficiente problematização sobre a inclusão no campo da Psicologia, sendo que, muitas vezes, esta parece ser vista muito relacionada à inclusão escolar, estando mais ligada, assim, ao campo da Pedagogia, sendo que à Psicologia caberia subsidiar as ações inclusivas - tanto em um sentido adaptacionista/corretivo, de tratamento e acompanhamento das crianças incluídas, como de intervenções mais amplas, como, por exemplo, projetos no sentido de potencializar as aprendizagens das crianças ou ações de sensibilização da comunidade escolar em relação à educação inclusiva. 
Porém, argumentamos aqui que, nas últimas décadas, somos convidados(as)/convocados(as) à inclusão em variados espaços e de distintas formas, em um cenário caracterizado pela ideia da inclusão como imperativo (Lopes, 2009), no qual a inclusão é um ideal a ser perseguido, em uma suposta oposição à exclusão. A partir da compreensão de que "o discurso está na ordem das leis" (Foucault, 1998, p. 7) e que, portanto, não podemos falar de qualquer coisa, pois aquilo que é marcado como verdadeiro deve sempre obedecer a determinadas regras, afirmamos que tal incitação obedece a uma ordem discursiva. Nessa perspectiva, também a Psicologia obedece ao imperativo da inclusão, sendo que psicólogos(as) são convocados(as) a realizar práticas entendidas como inclusivas. Para muito além do espaço escolar, portanto, a inclusão se torna um valor a ser perseguido, inscrevendo-se nas práticas psicológicas como determinadas programações de condutas tidas como desejadas e com efeitos de prescrição em relação ao que deve ser feito ou evitado.

Tendo isso em vista, este texto discute o que denominamos como incitação à inclusão na contemporaneidade, através das campanhas veiculadas na mídia impressa. Compreendemos, assim, que a visibilidade dada na mídia às campanhas inclusivas inscreve-se em uma lógica na qual todos precisam incluir e ser incluídos. A palavra campanha, em língua portuguesa, reveste-se de diferentes significados. Para além dos referentes a questões geográficas, chamamos a atenção para três conjuntos de significados que são, de certa forma, complementares: publicitários, militares e políticos. Assim, conforme um dicionário de língua portuguesa (Michaelis, 2016), campanha consiste em uma série de determinadas operações ou esforços sistemáticos enviados para a obtenção de um resultado específico, sendo que, em uma acepção publicitária, é o conjunto de anúncios divulgados em jornais, revistas, rádio, televisão ou outros meios e ações, como promoções, eventos, exposições etc., com o objetivo de promover os benefícios de um serviço, uma marca, uma ideia, uma causa etc., ou as qualidades de uma pessoa, de modo a conquistar o público consumidor e a torná-lo vendável ou aceito; numa acepção militar, refere-se a uma série de operações militares levadas a efeito, em um certo local e em tempo determinado, comumente empreendidas em períodos de guerra; por fim, no caso da política, diz respeito ao conjunto de procedimentos, em geral liderado e levado a efeito por um partido político ou grupo representativo, cujo objetivo é convencer as autoridades constituídas quanto às vantagens ou prejuízos de adoção de certa medida ou execução de um projeto, ou ainda quanto à escolha e/ou nomeação de um indivíduo para um cargo político.

Destacamos, para efeitos da discussão aqui proposta, esse entrelaçamento entre as acepções publicitárias, militares e políticas da palavra campanha, as quais mesclam questões relativas à 
definição (série de operações ou esforços sistemáticos; conjunto de anúncios; série de operações desenvolvidas em local e tempo determinado; conjunto de procedimentos) e objetivos (visando um resultado específico; buscando promover um serviço, uma causa, uma ideia para conquistar o público consumidor; no intuito de convencer as autoridades quanto às vantagens ou prejuízos de certas medidas). Dessa primeira aproximação, podemos perceber que campanhas são conjuntos de ações ou medidas que adquirem uma ação estratégica, seja no sentido de atingir determinado fim, seja no sentido de sensibilização ou convencimento da adoção de determinadas atitudes.

Nessa perspectiva, considerando-se que a mídia exerce uma função importante na produção e difusão de discursos, discutimos as campanhas como estratégias que visam a educar para a inclusão, argumentando como essas nos constituem como sujeitos inclusivos/as. Além disso, buscamos compreender de que forma os discursos da Psicologia se entrelaçam à produção de verdades sobre inclusão, mediante a constituição do que Foucault (2003) chama de regime de práticas, isto é, um lugar de encadeamento entre o que se diz e o que se faz, bem como das regras e das razões para os mesmos.

\section{Sobre o método: As campanhas sobre inclusão como estratégias educativas}

O direcionamento para as campanhas inclusivas deu-se a partir de uma pesquisa realizada sobre inclusão e mídia, que teve como materialidade de análise as edições de segunda à sexta-feira do jornal Zero Hora, com circulação na região Sul do Brasil, no período de março a dezembro de 2015. Durante a sistematização dos dados, percebemos que, dentre todos os materiais selecionados (reportagens, colunas, propagandas ou notas que veiculassem alguma ação relativa à inclusão, independentemente do detalhamento dado pelo jornal), havia uma parcela importante que se referia a campanhas relacionadas à inclusão. Dessa maneira, foi realizado um recorte relativo aos materiais que, no período mencionado, de alguma forma, aludiam a campanhas inclusivas, tendo sido selecionados, por este critério, 23 materiais. Ressalta-se que as 23 reportagens utilizadas para este estudo se referem a 21 campanhas inclusivas, sendo que duas campanhas aparecem em duas reportagens (Vamos juntas? e Coleta de lacres de latinhas para trocar por cadeira de rodas).

Na perspectiva teórica adotada, mais do que a descrição do um método, tal como concebido nas formas mais tradicionais de fazer pesquisa, compreendemos que é necessário assumir uma postura de 
problematização. Interessa-nos, tal como propõe Foucault (2003), não o sentido do discurso, mas sua função, buscando como se estabelecem as relações entre os acontecimentos discursivos. Os conceitos se constituem, nessa perspectiva, como ferramentas que possibilitam um certo modo de interrogar.

É necessário assinalar que, ao estudar as campanhas sobre inclusão veiculadas no jornal Zero Hora, não partimos de uma noção de que a mídia manipula ou se constitui como um veículo ideológico, pois, ao trabalhar em uma perspectiva foucaultiana de poder, não se trata de localizar o poder em determinado ponto, nem de considerá-lo como vertical e coercitivo, numa lógica que dividiria o mundo entre oprimidos e opressores. Deleuze (2005) pontua que, para Foucault, o poder se define como uma relação de forças, não se constituindo como uma forma e sempre se dando em relação com outras forças. Como uma ação sobre ações possíveis, o poder não se define pela violência, pois "a força não tem outro objeto além de outras forças" (p. 78). A partir dessas considerações, nossa análise sobre as campanhas midiáticas busca compreender como o poder se exerce, não concebendo a mídia como um ponto central de sua difusão, mas relações de poder que são difusas e instáveis, que "vão a cada instante de um ponto a outro no interior de um campo de forças, marcando inflexões, retrocessos, retornos, giros, mudanças de direção, resistências" (Deleuze, 2005, p. 81), não sendo localizáveis em uma determinada instância.

Além disso, é necessário desnaturalizar tanto aquilo que se coloca como uma verdade de nosso tempo, quanto o próprio binômio inclusão $x$ exclusão. Ao dizer isso, não se trata de negar a importância dos movimentos inclusivos ou denunciar a ideia de inclusão como falsa, inadequada ou insuficiente, mas pensá-la como uma produção sócio-histórica. Nessa direção, a análise realizada por Pinto (1999), referente aos sujeitos e grupos incluídos nas diferentes constituições brasileiras, evidencia que os movimentos de inclusões e exclusões que ocasionaram a delimitação de distintos sujeitos de direito resultaram tanto das condições históricas, como de determinadas estratégias e escolhas, as quais definiram, em cada época, quem eram os cidadãos brasileiros. Além disso, cabe apontar uma das críticas da autora à utilização que se faz, especialmente a partir dos anos 1990, dos termos incluídos e excluídos: a noção de excluído, ao substituir uma série de sujeitos sociais que tinham suas vidas marcadas por relações de desigualdade, dilui a materialidade de tais sujeitos, os quais passam a pertencer a uma massa disforme nomeada como 'excluída'. Tal questão acarreta em dois grandes efeitos: por um lado, o sujeito excluído perde sua unidade corpórea, pois todos podem ser excluídos em determinado momento; e, por outro, não se estabelece uma relação de antagonismo, pois o excluído não luta contra o incluído (como no caso, por exemplo, do 
proletariado em sua relação com a burguesia), mas, pelo contrário, almeja se tornar um deles. Portanto, para a autora, o binômio inclusão/exclusão evita a manifestação das contradições.

Em um debate com estudantes de Los Angeles, Foucault (2003, p. 253) enfatiza que "o poder é alguma coisa que opera através do discurso, já que o próprio discurso é um elemento em um dispositivo estratégico de relações de poder". Dessa maneira, o que está em questão não é a interpretação de um suposto sentido do discurso, mas sua função, tendo em vista o fato de que algo pode ser dito em um momento dado. Para isso, o autor coloca que seu tema é o discurso verdadeiro/falso, isto é, entender como o discurso entra no jogo do verdadeiro e do falso (Foucault, 1998), e, num momento posterior de sua obra, como se dá o governo dos homens pela verdade (Foucault, 2014).

Dessa maneira, os materiais referentes a campanhas inclusivas utilizados para a análise foram examinados não no sentido de uma suposta intencionalidade do sujeito falante (ou do jornal), mas das "diferentes maneiras pelas quais o discurso desempenha um papel no interior de um sistema estratégico em que o poder está implicado, e para o qual o poder funciona" (Foucault, 2003, p. 251). Além disso, entendemos, de acordo com Fischer (2002), que a mídia opera na construção de sujeitos e subjetividades, uma vez que "produz imagens, significações, enfim, saberes que de alguma forma se dirigem à 'educação' das pessoas, ensinando-lhes modos de ser e estar na cultura em que vivem" (p.153). Portanto, a mídia educa ou, como assinala a autora acima citada, atua como um dispositivo pedagógico, agindo na produção de sentidos e sujeitos na cultura. A partir de tais considerações, trazemos, a seguir, os resultados e a discussão realizada a partir da pesquisa.

\section{Sobre os resultados e a discussão de dados: Campanhas para inclusão}

Como trazido anteriormente, a noção de campanha está estreitamente vinculada à estratégia. Ao discutir os sentidos da palavra estratégia, Foucault (2010a) salienta que seu emprego se dá em 3 direções: 1) sobre a racionalidade utilizada para atingir um objetivo; 2) para designar as formas pelas quais se procura obter alguma vantagem sobre o outro; e 3) para nomear o conjunto de ações usados em um confronto com vistas a alcançar a vitória sobre o adversário. Tais sentidos são relativos, portanto, a situações de confronto, nos quais se busca agir de forma a escolher soluções tidas como vencedoras. Assim, estratégia tanto pode se referir aos meios utilizados para fazer operar ou manter um dispositivo de poder, quanto uma ação sobre as ações possíveis, no intuito de condução de 
condutas, ou, ainda, na resistência diante das relações de poder, visto que essas vão sempre implicar em algum tipo de estratégia de luta.

A partir do campo da publicidade, pode-se pensar que as campanhas inclusivas de que trata este artigo se aproximam do marketing social. Segundo Fontes (2001), a transposição do conceito de marketing para a área social aconteceu inicialmente no campo da saúde pública, objetivando a conscientização da população e a promoção de mudanças de hábitos e comportamentos. Barbosa (2012), ao analisar campanhas de doação de sangue, afirma o marketing social como uma potente ferramenta para lidar com questões necessárias a vida em sociedade, instigando uma melhora no bem estar social através de ações que promovam benefícios comuns. Nesse contexto, as peças publicitárias são um meio de sensibilizar e fazer agir os cidadãos em prol de projetos que se direcionem para uma coletividade (Gonçalves, 2004). As campanhas inclusivas, portanto, emergem na tentativa de convidar, provocar ou modificar comportamentos sociais.

Se campanhas se constituem como conjunto de procedimentos que tem o intuito de alcançar um determinado resultado, podemos perguntar: quais estratégias elas mobilizam? É possível pensarmos que, como estratégias, as campanhas operam tanto no sentido do poder, quanto de resistência? Deleuze (2005) aponta que as relações de poder são estratégicas, distinguindo-se das estratificações, "são quase mudas e cegas, pois escapam às formas estáveis do visível e do enunciável" ( $p .81$ ). Para o autor, justamente pelo poder não ser conhecido, não ser redutível à prática do saber, é que se pode falar em uma microfísica: não como uma miniaturização, mas como um novo domínio marcado por ligações móveis e não-localizáveis.

Com a intenção de melhor visibilizar as campanhas para a análise, as mesmas foram agrupadas em tabelas: a primeira para demonstrar os sujeitos da inclusão, a segunda apresentando as estratégias e ações inclusivas, e a terceira, por fim, expressando as justificativas para tais campanhas. Nesse sentido, uma mesma campanha pode estar citada duas vezes em uma mesma tabela, já que ela pode se endereçar a diferentes sujeitos ou apresentar mais de uma ação inclusiva ou justificativa. Em vista disso, a somatória de campanhas em uma mesma tabela pode ser superior ao número total de materiais analisadas (23 reportagens, 21 campanhas diferentes). 
Tabela 1

Quem são os Sujeitos da Inclusão?

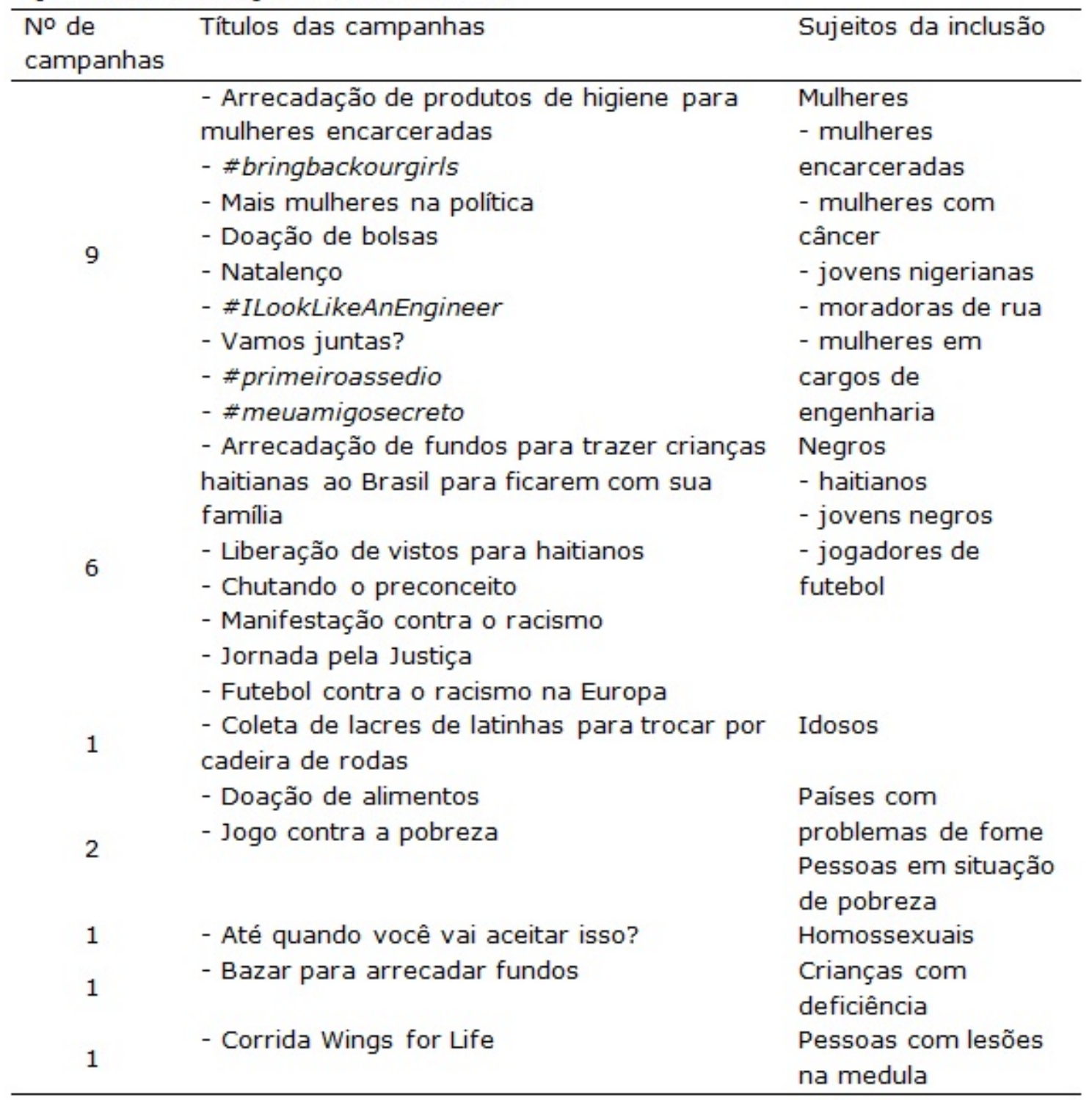

Para Fischer (2001, p. 212), a mídia se constitui como um espaço onde muitas instituições e sujeitos se expressam, sendo que "a marca da heterogeneidade, além de ser bastante acentuada, é quase definidora da formação discursiva em que se insere". A partir disso, podemos afirmar que as campanhas analisadas voltam-se justamente para essa heterogeneidade, multiplicando os sujeitos passíveis de inclusão: pessoas com deficiência, mulheres, negros/as, imigrantes, idosos, moradores/as de rua, refugiados/as, pobres, homossexuais, pessoas com câncer... Se, por um lado, as diferenças são enunciadas e tornadas visíveis, havendo uma busca de redução de preconceitos, melhoria das condições de vida e chamamentos à solidariedade, por outro lado percebemos que esse outro a ser incluído é marcado pela noção de falta, sendo que seus contornos são dados a partir da 
distância que o separa daquilo que é definido como padrão (homem, branco, heterossexual, classe média, saudável, 'normal', etc.).

Nessa perspectiva, as campanhas participam dos jogos de saber/poder em que há "uma regulação e um controle que define para onde olhar, como olhamos quem somos nós e quem são os outros e, finalmente, como o nosso olhar acaba por sentenciar como somos nós e como são os outros" (Skliar, 2003, p. 71). Portanto, ao enunciar quem são os sujeitos passíveis de inclusão e convocar para que os leitores sejam agentes inclusivos, as campanhas também ofertam determinadas maneiras de agir e de pensar, demarcando os lugares que devem (e como devem) ser ocupados na relação com o outro. Nesse sentido, a multiplicação das diferenças e o alargamento dos sujeitos passíveis de inclusão possibilitam também outros modos de existir, pois, conforme discutido por Hacking (2009, p. 123), "quem somos não é apenas o que fizemos, fazemos e faremos, mas também o que poderíamos ter feito e o que podemos vir a fazer".

No que concerne aos sujeitos a serem incluídos, vemos que o maior número de campanhas volta-se para mulheres. Tal resultado pode ser pensado como efeito da emergência e proliferação dos discursos feministas, que, de acordo com Costa (2002), tem colocado em pauta a articulação das diversas posições de sujeitos, possibilitando espaço para agenciamentos e resistência. De modo semelhante, as lutas contra a discriminação racial, juntamente aos movimentos migratórios nos últimos anos, abre espaço para a visibilidade da situação das pessoas negras, atentando para a necessidade de ações inclusivas para tais sujeitos. As campanhas inclusivas, assim, podem ser pensadas como movimentos de resistência, relacionadas às lutas de diferentes movimentos sociais, já que, ao visibilizarem identidades não hegemônicas, disputam os jogos de poder e verdade, legitimando existências outras.

Se tomarmos a célebre frase de Foucault (1985, p. 91), “lá onde há poder há resistência", é necessário atentar que tal afirmação não estabelece a resistência numa posição de exterioridade em relação ao poder. Ao contrário, é justamente pelo entendimento de que o poder só pode existir mediante os inúmeros pontos de resistência que funcionam como oposição, exercendo uma função de apoio, de saliência, para as relações de poder. Dessa maneira, resistência deve ser compreendida no plural - resistências - não se constituindo como um lugar da grande recusa, mas lutas pontuais: "possíveis, necessárias, improváveis, espontâneas, selvagens, solitárias, planejadas, arrastadas, violentas, irreconciliáveis, prontas ao compromisso, interessadas ou fadadas ao sacrifício" (p. 91), inscrevendo-se, assim, em um campo estratégico. Além disso, é preciso ter claro que não se trata do negativo das relações de poder, como se fossem uma espécie de subproduto das mesmas. As resistências não podem ser reduzidas a poucos princípios 
heterogêneos. Embora às vezes possam resultar em grandes rupturas, o mais frequente é que se pulverizem pelo tecido social, como pontos móveis e transitórios. Assim, “um exercício de poder aparece como um afeto, já que a própria força se define por seu poder de afetar outras forças (com as quais ela está em relação) e de ser afetada por outras forças" (Deleuze, 2005, p. 79). Por isso, diferente da violência que destrói ou altera as formas de corpos e objetos, o poder se exerce mediante afetos ativos, os quais incitam, seduzem, produzem, suscitam, etc., não se dando somente como influência, repercussão ou de forma passiva, visto que a força afetada sempre tem capacidade de resistência.

Tendo em vista, portanto, quais são os sujeitos que são produzidos, pelo jornal, como passíveis de inclusão, apresentamos, a seguir, as estratégias utilizadas para que a inclusão aconteça (Tabela 2). 
Tabela 2

Ações Inclusivas Relacionadas às Campanhas

\begin{tabular}{|c|c|c|}
\hline $\begin{array}{l}N^{\circ} \text { de } \\
\text { campanhas }\end{array}$ & Títulos das campanhas & Ações inclusivas \\
\hline 10 & $\begin{array}{l}\text { - Arrecadação de produtos de } \\
\text { higiene para mulheres } \\
\text { encarceradas } \\
\text { - Doações de bolsas } \\
\text { - Natalenço } \\
\text { - Bazar para arrecadar fundos } \\
\text { - Doação de alimentos } \\
\text { - Corrida Wings for Life } \\
\text { - Arrecadação de fundos para } \\
\text { trazer crianças haitianas ao Brasil } \\
\text { para ficarem com sua família } \\
\text { - Coleta de lacres de latinhas para } \\
\text { trocar por cadeira de rodas } \\
\text { - Vamos juntas? } \\
\text { - Jogo contra a pobreza }\end{array}$ & $\begin{array}{l}\text { Arrecadações de dinheiro, } \\
\text { roupas, comida, produtos de } \\
\text { higiene, de autocuidado, ou } \\
\text { lacres de latinhas }\end{array}$ \\
\hline 4 & $\begin{array}{l}\text { - \#bringbackourgirls } \\
\text { - \#ILookLikeAnEngineer } \\
\text { - \#primeiroassedio } \\
\text { - \#meuamigosecreto } \\
\text { - Chutando o preconceito } \\
\text { - Corrida Wings for Life }\end{array}$ & $\begin{array}{l}\text { Movimentos de visibilidade e } \\
\text { denúncia de violências de } \\
\text { gênero em redes sociais como o } \\
\text { Instagram, Twitter e Facebook } \\
\text { Esporte como estratégia } \\
\text { inclusiva }\end{array}$ \\
\hline 4 & $\begin{array}{l}\text { - Jogo contra a pobreza } \\
\text { - Futebol contra o racismo na } \\
\text { Europa }\end{array}$ & \\
\hline 2 & $\begin{array}{l}\text { - Mais mulheres na política } \\
\text { - Liberação de vistos para } \\
\text { haitianos }\end{array}$ & Políticas públicas \\
\hline 2 & $\begin{array}{l}\text { - Manifestação contra o racismo } \\
\text { - \#bringbackourgirls }\end{array}$ & Manifestações nas ruas \\
\hline $\begin{array}{l}1 \\
1\end{array}$ & $\begin{array}{l}\text { - Até quando você vai aceitar isso? } \\
\text { - Jornada pela Justiça }\end{array}$ & $\begin{array}{l}\text { Propaganda midiática } \\
\text { As ações não são explicitadas } \\
\text { na reportagem }\end{array}$ \\
\hline
\end{tabular}

Morcerf e Almeida (2006) apontam que o marketing social pretende atingir quatro mudanças sociais: cognitiva, de ação, de comportamento, de valor. A primeira diz respeito a programas e campanhas que visem informar a população e/ou chamar atenção para problemáticas sociais, tais como a pobreza e a intolerância. A segunda, mudança de ação, tem como objetivo promover uma ação específica, podendo ser a de que jovens retomem os estudos ou de que pessoas contribuam com doações para causas sociais, seja de dinheiro, sangue ou órgãos. A terceira, mudança de comportamento, está associada a campanhas que pretendem desencorajar hábitos 
nocivos à saúde, fomentando o bem estar individual. Por fim, mudança de valor, corresponde a campanhas que promovam a alteração de ideias, a formação de opinião, incentivando o respeito e ações práticas contra a intolerância. Na esteira dessa argumentação, podemos observar que as campanhas inclusivas dispostas no jornal compartilham da busca pela mudança de atitudes no tecido social, ao passo em que ofertam modelos e ações a serem seguidos.

Transpondo a discussão realizada por Foucault (1985) a respeito do dispositivo da sexualidade, também podemos pensar que não há uma estratégia universal, válida para toda a sociedade e que se distribua de modo uniforme no que se refere à inclusão. Entretanto, o que podemos observar é uma inventividade constante, que se evidencia por uma multiplicidade de métodos e procedimentos que nos fazem ver e falar sobre a inclusão, fabricando-nos como sujeitos inclusivos. É neste ponto que a noção de campanhas como estratégia ganha força: as campanhas veiculadas pelo jornal são múltiplas e dirigem-se a variados sujeitos (tanto aqueles tidos como passíveis de inclusão, quanto os potenciais sujeitos inclusivos) - não se distribuem de forma homogênea, pulverizam-se por entre as edições do jornal, recebem diferentes destaques e tratamentos. Há campanhas de todos os tipos, tamanhos e objetivos; voltadas para a arrecadação de bichos de pelúcia, alimentos e roupas para doação, organizadas por instituições ou por pessoas que se sentiram chamadas a ajudar alguém que passava por necessidades específicas; criadas e veiculadas nas redes sociais utilizando-se de hashtags para visibilizar desigualdades de gênero ou violências, campanhas que emergem através da iniciativa de crianças, como a de uma menina que com 8 anos de idade que coleta lacres de latinhas para trocar por cadeiras de rodas para idosos, ou, ainda, aquelas organizadas pelos órgãos governamentais, a fim de garantir a participação de mais mulheres na política ou facilitar a liberação de vistos para haitianos.

Entre as ações inclusivas, destacam-se a arrecadação de roupas, comida, dinheiro, lacres de latinha ou materiais em geral. Há, portanto, a presença de uma cultura de doação de recursos como estratégia inclusiva, relacionada com um discurso de caridade. A Pesquisa Doação Brasil, realizada em 2015, aponta que a questão da doação é transpassada pelas dimensões culturais, ambientais e de escolha individual, e, nesse sentido, algumas campanhas sensibilizam mais do que outras. A pesquisa demonstrou que a sensibilidade dos brasileiros volta-se mais fortemente para doações endereçadas a grupos mais frágeis e vulneráveis, como crianças, idosos e pessoas em situação de pobreza, corroborando com os resultados da pesquisa que fundamenta este artigo. Além disso, como discutido por Winter (2016), em seu trabalho sobre os discursos sobre as políticas públicas de assistência social produzidos no Jornal Zero Hora, embora, após a Constituição Federal de 1988 busque substituir a ideia da caridade 
pela cidadania (que tem como alvo um sujeito de direitos), a noção de benevolência ainda é bastante arraigada na nossa sociedade.

Além disso, destaca-se o uso de redes sociais como o Facebook, Twitter e Instagram para o lançamento e visibilidade de campanhas, especialmente aquelas ligadas à desigualdade de gênero e violência contra mulher. Das 21 campanhas selecionadas para esse estudo, 5 apresentavam alguma relação com o ambiente virtual. Dessa maneira, na reportagem União virtual para inibir situações de risco reais (2015, p.27), Babi Souza e Vika Schmitz comentam sobre o movimento Vamos Juntas?. Elas criaram um projeto e publicaram em seus perfis no Facebook convidando mulheres a andarem juntas na rua, a fim de inibir situações de risco. Em aproximadamente duas horas o movimento ganhou uma página virtual e, até a noite, 20 mil pessoas já haviam curtido a página. No Instagram, rede social de fotos, a campanha foi mencionada em 34.327 publicações públicas.

As demais campanhas contam com o apoio de hashtags, palavrachave antecedida pelo símbolo cerquilha (\#), utilizada para identificar a temática do que as pessoas estão compartilhando nas redes sociais, para sua consolidação ou visibilidade. É o caso das campanhas \#bringbackourgirls (2015, p. 14), nascida um dia após 276 adolescentes serem sequestradas na cidade de Chibok, no estado de Borno, Nigéria, e citada 277.627 vezes em publicações públicas no Instagram, como é possível visualizar no aplicativo; \#meuamigosecreto (2015, p. 36), mobilização contra a desigualdade de gênero onde usuários relatam comportamentos cotidianos de machismo velado, utilizada 8.593 vezes na rede social mencionada; \#primeiroassédio (2015, p. 30), lançada pelo coletivo feminista Think Olga, após alguns telespectadores do MasterChef Júnior se utilizarem do Twitter para expressar mensagens de teor sexual em relação a uma participante de 12 anos, citada em 2.517 publicações públicas; e \#ilooklikeanengineer (2015, p. 23), mencionada 22.632 vezes no Instagram.

Diante dos expressivos números de publicações virtuais citando campanhas, pode-se pensar no espaço que o ciberativismo vem conquistando nos últimos anos. Segundo Santos (2011), esse movimento se fortalece no Brasil em meados dos anos 90, através do "avanço da internet e a entrada de ativistas políticos, sociais e ambientalistas na rede (...) com isso a rede se torna um espaço "público" em que os ativistas podem se manifestar, otimizando o impacto de suas ideias" (p. 3). Além disso, salienta que esse uso das redes sociais carrega consigo uma proposta de conscientização através da internet.

$\mathrm{Na}$ esteira da visibilidade, podemos apontar ainda as ações vinculadas às manifestações na rua ou campanhas midiáticas. Há, também, um movimento de inclusão pelo esporte, tratando-se aqui, especificamente, de eventos esportivos ou campanhas relacionadas 
ao futebol que visam conscientizar a população sobre o racismo ou arrecadar fundos para questões relacionadas à pobreza.

Entretanto, destacamos que, no conjunto das reportagens analisadas, há apenas duas que articulam as ações inclusivas às políticas públicas. Tal rarefação das políticas públicas fica ainda mais evidente diante do volume das campanhas que propõem ações caritativas, especialmente referentes à arrecadação de donativos para os diferentes sujeitos a serem incluídos. Nessa perspectiva, concordamos com Winter (2016) quando conclui que "os discursos do jornal enunciam que os direitos destes 'estranhos' são associados à caridade, a boas ações e não a uma política que lhes garanta direitos" (p. 70).

Percebe-se que a nomeação/identificação dos sujeitos que devem ser incluídos faz proliferar possibilidades de ação para a realização da inclusão. Conforme discutido por Hacking (2009), quando se criam novos modos de descrição, outras possibilidades de agir passam a existir. Portanto, na medida em que se criam mais sujeitos passíveis de inclusão, também se intensificam as criações de estratégias para fazer com que todos participem desse jogo: tanto os que devem ser incluídos, quanto os que devem ser agentes de inclusão.

Frente à pluralidade de campanhas e à diversidade de sujeitos a quem se destinam, as justificativas para as mesmas são as mais variadas. A tabela apresentada a seguir busca sistematizar tais justificativas, embora, como pode ser observado, a própria variedade das justificativas gera uma dificuldade em realizar agrupamentos: 
Tabela 3

Justificativas para as Campanhas

\begin{tabular}{|c|c|c|}
\hline $\begin{array}{l}\text { No de } \\
\text { campanhas }\end{array}$ & Títulos das campanhas & $\begin{array}{c}\text { Justificativas para as ações } \\
\text { propostas }\end{array}$ \\
\hline 5 & $\begin{array}{l}\text { - Coleta de lacres de latinhas para } \\
\text { trocar por cadeira de rodas ( } 2 \\
\text { reportagens) } \\
\text { - Arrecadação de fundos para } \\
\text { trazer crianças haitianas ao Brasil } \\
\text { para ficarem com sua família } \\
\text { - Doações de bolsas } \\
\text { - Natalenço }\end{array}$ & $\begin{array}{l}\text { Ajudar ao próximo e se tornar } \\
\text { um ser humano melhor. Realizar } \\
\text { doações como um ato de amor e } \\
\text { cuidado com quem precisa. }\end{array}$ \\
\hline 6 & $\begin{array}{l}\text { - \#bringbackourgirls } \\
\text { - \#ILookLikeAnEngineer } \\
\text { - \#primeiroassedio } \\
\text { - \#meuamigosecreto } \\
\text { - Vamos juntas? (2 reportagens) }\end{array}$ & $\begin{array}{l}\text { Necessidade de combater o } \\
\text { assédio e a violência contra a } \\
\text { mulher, visibilizando tais atos. }\end{array}$ \\
\hline 4 & $\begin{array}{l}\text { - Doação de alimentos } \\
\text { - Cerco ao racismo } \\
\text { - Manifestação contra o racismo } \\
\text { - Jornada pela Justiça }\end{array}$ & Sem justificativa na reportagem. \\
\hline 1 & $\begin{array}{l}\text { - Até quando você vai aceitar } \\
\text { isso? }\end{array}$ & $\begin{array}{l}\text { Contestar a discriminação de } \\
\text { gênero e orientar sobre a } \\
\text { importância do uso do cinto de } \\
\text { segurança. }\end{array}$ \\
\hline 1 & - Mais mulheres na política & $\begin{array}{l}\text { Ampliar a participação feminina } \\
\text { na política. }\end{array}$ \\
\hline 1 & $\begin{array}{l}\text { - Liberação de vistos para } \\
\text { haitianos }\end{array}$ & $\begin{array}{l}\text { Impedir o avanço do tráfico de } \\
\text { seres humanos e diminuir a } \\
\text { travessia feita pelos coiotes. }\end{array}$ \\
\hline 1 & - Contra a pobreza & Erradicar o Ebola. \\
\hline 1 & $\begin{array}{l}\text { - Arrecadação de produtos de } \\
\text { higiene para mulheres } \\
\text { encarceradas }\end{array}$ & $\begin{array}{l}\text { Diminuir a precariedade em que } \\
\text { vivem as mulheres } \\
\text { encarceradas. }\end{array}$ \\
\hline 1 & - Bazar para arrecadar fundos & $\begin{array}{l}\text { Manter a instituição } \\
\text { funcionando. }\end{array}$ \\
\hline 1 & - Chutando o preconceito & $\begin{array}{l}\text { Diminuir o racismo no futebol } \\
\text { através de pequenas atitudes } \\
\text { que podem tornar o mundo } \\
\text { melhor. }\end{array}$ \\
\hline 1 & - Corrida Wings for Life & $\begin{array}{l}\text { Visibilizar a questão das pessoas } \\
\text { que possuem lesão na medula e } \\
\text { ajudar a resolver o problema. }\end{array}$ \\
\hline
\end{tabular}

Entre as justificativas para as campanhas, estão a necessidade de ajudar o próximo e de se tornar uma pessoa melhor, visibilizar violências de gênero, solucionar problemas específicos, diminuir o racismo, assegurar o lugar das mulheres na política e etc. Quatro 
campanhas não apresentavam justificativas explícitas, mas suas causas ficavam visíveis: uma campanha se destinava à arrecadação de comida e as outras três estavam articuladas com a questão do racismo. De qualquer modo, é possível perceber que as justificativas das campanhas se constituem como uma forma de legitimação da inclusão, a qual, se consolidada, permitiria uma sociedade tida como mais justa e melhor. Para tanto, é necessário que todos se engajem nessa construção. Nas palavras de Thoma e Kraemer (2011), uma sociedade inclusiva pressupõe que

todos devem estar cientes de sua responsabilidade, de seus valores éticos e morais, bem como de sua frágil condição humana. Somos reiteradamente convidados a refletir sobre aquilo pelo qual lutamos e acreditamos, e para isso deve-se possibilitar que todos convivam, circulando nos mesmos espaços e com as mesmas condições (p. 217).

\section{Produção de verdades sobre inclusão: E a Psicologia?}

Uma das questões sobre as quais Foucault (2010b) se debruça em seus anos finais diz respeito às formas pelas quais nos tornamos sujeitos, ou melhor, as relações entre subjetividade e verdade. Para ele, se o que caracteriza a Modernidade é o entendimento de que o acesso à verdade se dá somente pela via do conhecimento, na Antiguidade postulava-se que "não pode haver verdade sem uma conversão ou sem transformação do sujeito" (Foucault, 2010b, p. 16), sendo que tal conversão ou transformação ocorreria mediante diferentes caminhos que implicariam um trabalho sobre si. Entretanto, o autor chama a atenção para que tal corte, denominado de momento cartesiano, tenha sido feito de forma abrupta e definitiva, pois é possível perceber inúmeros pontos de fricção entre esses diferentes modos de conceber as relações entre sujeito e verdade. $\mathrm{E}$, entre os exemplos dessas superfícies de contato, traz a psicanálise e o marxismo como formas de saber que possibilitam um trabalho sobre si como condição de acesso à verdade.

$\mathrm{Na}$ medida em que afirmamos que vivemos hoje sob um imperativo da inclusão, é necessário perguntar como nos tornamos sujeitos inclusivos, ou seja, partícipes dessa sociedade que se quer inclusiva. Nesse sentido, as campanhas podem ser vistas como estratégias de convencimento, operando pelo viés do conhecimento: aqueles que incluem são pessoas tidas como mais esclarecidas, iluminadas pela verdade da inclusão. Por outro lado, o engajamento contínuo em campanhas que visam a combater a desigualdade e a discriminação também pode ser compreendido como um chamamento para que os sujeitos dobrem-se à inclusão, assumindo determinadas ações sobre 
si no sentido de sua transformação, examinando suas práticas e buscando aproximá-las da verdade. Ou seja, mais do que um ato de conhecimento, parece estar em questão a própria transfiguração do sujeito em um sujeito inclusivo.

Nessa perspectiva, algumas das campanhas apoiam-se na figura de determinados personagens que são compreendidos como exemplos de histórias bem-sucedidas de inclusão, assumindo um duplo caráter, isto é, sujeitos incluídos e inclusivos, visto que as campanhas são espaços de promoção de ações que diminuam o preconceito e garantam a inclusão de outros sujeitos. Evidencia-se, portanto, que a tarefa de incluir se estende a todos, inclusive àqueles que já foram incluídos.

É necessário marcar que, embora muitas das campanhas selecionadas não tratem diretamente da inclusão (no sentido de não trazê-la explicitamente em seu enunciado), percebe-se que objetivam sensibilizar para determinadas noções que, costumeiramente, são associadas à mesma, tais como diversidade, tolerância, solidariedade, respeito e direito à diferença. Sem entrar no mérito de tais noções, no sentido de qualificá-las como suficientes ou insuficientes, ou mesmo apontar-Ihes as limitações, cabe dizer que existe um aspecto a que todas as campanhas confluem: elas se destinam aos sujeitos tidos como diferentes, sendo que a diferença é compreendida dentro de uma lógica de normalidade/anormalidade. Nessa perspectiva, a diferença é definida a partir de uma identidade como norma. Conforme discutido por Silva (2011), normalizar implica em eleger uma identidade que servirá de parâmetro para outras, que terá o status de natural, não será encarada como uma identidade, mas como a identidade, portanto, "a força homogeneizadora da identidade normal é diretamente proporcional à sua invisibilidade" (p. 83). Desse modo, podemos pensar que, quanto menos uma identidade aparece, mais próxima da norma ela está, são identidades silenciadas (não no sentido de não terem voz, mas de sua naturalização), para as quais não se elaboram questionamentos. Inversamente, quanto mais visíveis e mencionadas, mais são comparadas, diferenciadas e hierarquizadas em relação ao padrão normativo.

Nessa perspectiva, a identidade e a diferença são inseparáveis. Uma depende da outra para sua existência e precisam ser ativamente produzidas (Silva, 2011). Assim, podemos pensar que, na contemporaneidade, a relação entre identidade e diferença é, muitas vezes, paradoxal. Como assinala Nardi (2013, p. 261), "a norma está em debate, ela tem perdido o seu caráter uniforme". Nessa direção, ao abordar especificamente as questões relacionadas à sexualidade, 0 autor discute como tanto os argumentos que denunciam 0 preconceito e buscam desconstruir aspectos tidos como naturais, quanto argumentos que essencializam identidades de gênero e sexuais, patologizando-as, podem ser encontrados em um mesmo 
campo de saber, como, por exemplo, na Psicologia. Trata-se, portanto, de um campo de tensão permanente.

Portanto, se como frisa Foucault (2016, p. 13), “não há teoria do sujeito independente da relação com a verdade", visto que não se pode pensar a subjetividade a partir de uma teoria prévia e universal, sendo que o sujeito é constituído na própria relação com a verdade e, além disso, "a verdade é antes de tudo um sistema de obrigações" (p. 13) e não um conhecimento universalmente válido, podemos compreender que as campanhas de inclusão são estratégias de convencimento e produção de sujeitos. Assim, o que está em jogo é "a verdade como vínculo, a verdade como obrigação, a verdade também como política" (Foucault, 2016, p. 14).

Tendo isso em vista, também é possível afirmar que as multifacetadas campanhas veiculadas na mídia, além de seu propósito mais explícito (arrecadar fundos, reduzir preconceito, mobilizar determinados grupos, etc.), também legitimam a inclusão e ampliam possibilidades de compreensão para identidades tidas como minoritárias para além de uma hierarquização entre normalidade e anormalidade, criando novos arranjos. As campanhas, assim, se constituem como estratégias educativas, ampliando a inclusão de variados sujeitos vistos como excluídos e, principalmente, subjetivando-nos a partir do imperativo da inclusão. Dessa forma, tais discursos nos colocam diante das perguntas: quem somos, como devemos ser, como devemos agir?

\section{Considerações Finais}

Tendo em vista a discussão realizada no presente artigo, entende-se que é necessário estar atento para os diferentes vetores que compõem o complexo panorama da inclusão. Se, por um lado, a norma se inscreve numa função política, operando como um princípio de inteligibilidade e de correção dos ditos anormais (Pagni, 2017), por outro, os efeitos do discurso da inclusão são difusos, sendo que sua multiplicação em distintas campanhas, de algum modo, atesta isso. Pode-se pensar que, ao nos constituir como sujeitos inclusivos, a própria norma é questionada, sendo que a diferença multiplica-se em distintos domínios (sexualidade, gênero, raça, deficiências, religião, etc.).

Nessa perspectiva, há um tensionamento constante, sendo que a inclusão se produz entre capturas e resistências. Possibilidades e impossibilidades se entrecruzam, as diferenças escapam, novas formas são inventadas, norma e normalizações se embaralham. Se, como argumenta Skliar (2001), os discursos sobre inclusão funcionam a partir de uma racionalidade fundada numa noção de diversidade que, aliada ao conceito de igualdade, acaba obscurecendo 
a própria diferença ou fomentando situações de inclusões excludentes, também, como coloca Pagni (2017, p. 257), não se trata de pensar a vida apenas "como algo a ser governado pelos dispositivos de subjetivação e pelas tecnologias do biopoder existentes, (...) como também se apresenta como potência que resta ou que excede a essas formas de seu governamento, resistindo-lhe e criando outros modos de existência".

A multiplicidade das campanhas nos provocam a pensar na complexidade do mundo em que vivemos, sendo que as variadas estratégias utilizadas nos convocam a entender a própria vida como palco de batalha. Ou, como convida Foucault (2004), considerando-se que a ética está diretamente implicada com a liberdade, trata-se de fazer da própria vida uma obra de arte, praticando a liberdade de determinada maneira. Além disso, é preciso pensar em que medida a Psicologia participa na construção de um discurso verdadeiro sobre a inclusão, mediante um sistema que produz a inclusão como um imperativo inquestionável que dispõe sujeitos (incluídos e inclusivos) em uma rede de obrigações.

\section{Referências}

Barboza, S. I. S. (2012). Marketing social aplicado à doação de sangue: fatores condicionantes de comportamento (Dissertação de mestrado). Universidade Federal da Paraíba, João Pessoa, PB. Recuperado de https://repositorio.ufpb.br/jspui/handle/tede/3807

Costa, C. L. (2002). O sujeito no feminismo: revisitando debates. Cadernos Pagu, (19), 59-90. doi:10.1590/S010483332002000200004

Deleuze, G. (2005). Foucault. São Paulo: Brasiliense.

Estreia de MasterChef Júnior suscita debate sobre participação de crianças em programas de competição. (2015, Outubro 23). Zero Hora, pp. 30.

Fischer, R. M. B. (2001). Foucault e a análise do discurso em educação. Cadernos de Pesquisa, (114), 197-223. doi: 10.1590/S0100-15742001000300009

Fischer, R. M. B. (2002). O dispositivo pedagógico da mídia: modos de educar na (e pela) TV. Educação e Pesquisa, 28(1), 151162. doi: 10.1590/S1517-97022002000100011

Fontes, M. (2001). Marketing Social Revisitado: Novos paradigmas do Mercado Social. Florianópolis: Cidade Futura.

Foucault, M. (1985). História da sexualidade I: A vontade de saber (7a ed.). Rio de Janeiro: Graal.

Foucault, M. (1998). A ordem do discurso (4a ed.). São Paulo: Edições Loyola. 
Foucault, M. (2003). Ditos e escritos IV: Estratégia, poder-saber. Rio de Janeiro: Forense Universitária.

Foucault, M. (2004). A ética do cuidado de si como prática da liberdade. In M. Foucault, Ditos e escritos V: Ética, sexualidade, política (pp. 264-287). Rio de Janeiro: Forense Universitária.

Foucault, M. (2010a). O sujeito e o poder. In H. L. Dreyfus, \& P. Rabinow, Michel Foucault: uma trajetória filosófica ( $2 a$ ed., pp. 273-295). Rio de Janeiro: Forense Universitária.

Foucault, M. (2010b). A hermenêutica do sujeito (3a ed.). São Paulo: WMF Martins Fontes.

Foucault, M. (2014). Do governo dos vivos. São Paulo: WMF Martins Fontes.

Foucault, M. (2016). Subjetividade e verdade. São Paulo: WMF Martins Fontes.

Gonçalves, G. M. P. (2004). Publicidade a causas sociais ou um olhar sobre a sua [in]eficácia. Biblioteca on-line de ciências da comunicação. Recuperado de http: // www. bocc.ubi.pt/pag/goncalves-gisela-publicidadesocial.pdf

Hacking, I. (2009). Inventando pessoas. In I. Hacking. Ontologia histórica (L. Mendes Trad., pp. 115-130). São Leopoldo: Editora UNISINOS.

Lopes, M. C. (2009). Políticas de inclusão e governamentalidade. Educação e Realidade, 34(2), 153-169. Recuperado de http://seer.ufrgs. br/educacaoerealidade/article/view/8297/553 6

Michaelis. (2016). Dicionário brasileiro de língua portuguesa. São Paulo: Melhoramentos. Recuperado de http: // michaelis.uol.com. br/busca? $r=0 \& f=0 \& t=0 \&$ palavra $=$ cam panha

Morcerf, S. O., \& Almeida, T. C. S. (2006). Marketing social: a estratégia de mudança do comportamento social. Cadernos UniFOA, (1) 1 , 1-14. Recuperado de http: // web.unifoa.edu.br/cadernos/edicao/01/71.pdf

Nardi, H. C. (2013). Diversidade sexual e políticas públicas: compreendendo os vetores de subjetivação e as transformações no dispositivo da sexualidade. In A. L. C. Brizola, A. V. Zanella, \& M. Gesser (Orgs.), Práticas sociais, políticas públicas e direitos humanos (pp. 249-265). Florianópolis: Abrapso.

Pagni, P. A. (2017). A emergência do discurso da inclusão escolar na biopolítica: uma problematização em busca de um olhar mais radical. Revista Brasileira de Educação, 22(68), 255-272. doi: 10.1590/s1413-24782017226813

Pinto, C. R. J. (1999). Foucault e as constituições brasileiras: quando a lepra e a peste se encontram com nossos excluídos. Revista Educação \& Realidade, 24(2), 33-57. Recuperado de 
https://seer.ufrgs. br/educacaoerealidade/article/view/55375/33 645

Santos, F. J. A. (2011). O ciberativismo como ferramenta de grandes mobilizações humanas: das revoltas no Oriente Médio às ações pacíficas do Greenpeace no Brasil. Revista Anagrama: Revista Científica Interdisciplinar da Graduação, 5(1), 1-7. Recuperado de

http://www.revistas.usp.br/anagrama/article/view/35590/3830 9

Silva, T. T. (2011). Identidade e diferença: a perspectiva dos estudos culturais (10a ed.). Petrópolis, RJ: Vozes.

Skliar, C. (2003). Pedagogia (improvável) da diferença: e se o outro não estivesse aí? (G. Lessa Trad.). Rio de Janeiro: DP\&A.

Skliar, C. (2001). Seis perguntas sobre a questão da inclusão ou de como acabar de uma vez por todas com as velhas - e novas fronteiras em educação: educação especial e políticas inclusivas. Pro-Posições, 12(2-3), 11-21. Recuperado de https://www.fe.unicamp.br/pf-fe/publicacao/2106/3536-dossieskliarc.pdf

Thoma, A. S., \& Kraemer, G. M. (2011). A arte de condução das condutas no contexto da educação inclusiva: premiando experiências escolares. In A. S. Thoma \& B. Hillesheim (Orgs.), Políticas de inclusão: gerenciando riscos e governando as diferenças (pp. 198-224). Santa Cruz do Sul, RS: Edunisc.

União virtual para inibir situações de risco reais. (2015, Agosto 4). Zero Hora, pp. 27.

Winter, G. F. (2016). Não nos damos conta disso: uma análise dos discursos produzidos a respeito das políticas públicas de Assistência Social no jornal Zero Hora (Dissertação de mestrado). Universidade de Santa Cruz do Sul, Santa Cruz do Sul, RS, Brasil.

\#bringbackourgirls. (2015, Abril 15). Zero Hora, pp. 14.

\#ilooklikeanengineer. (2015, Agosto 12). Zero Hora, pp. 23.

\#meuamigosecreto: conheça a campanha que expõe pensamentos machistas. (2015, Novembro, 26). Zero Hora, Porto Alegre, pp. 36.

\section{Endereço para correspondência \\ Betina Hillesheim}

Universidade de Santa Cruz do Sul

Programa de Pós-Graduação em Educação

Avenida Independência, 2293, bairro Universitário, CEP 96815-900, Santa Cruz do

Sul - RS, Brasil

Endereço eletrônico: betinah@unisc.br 


\section{Amanda Cappellari}

Rua Professor Juvenal Muler, 160, ap 21, bairro Rio Branco, CEP 90420-230, Porto Alegre - RS, Brasil

Endereço eletrônico: amandacappellari@gmail.com

Recebido em: 18/09/2018

Reformulado em: 23/12/2018

Aceito em: 25/01/2019

\section{Notas}

* Psicóloga, Doutora em Psicologia (PUCRS), professora adjunta e pesquisadora do departamento de Psicologia (UNISC), com atuação no Programa de Pós-Graduação (Mestrado e Doutorado) em Educação e no Mestrado Profissional em Psicologia.

** Graduada em Psicologia pela Universidade de Santa Cruz do Sul. Mestranda pelo Programa de Pós-Graduação em Psicologia Social e Institucional da Universidade Federal do Rio Grande do Sul. Bolsista CAPES.

Financiamento: CNPq; Fapergs; CAPES.

Este artigo de revista Estudos e Pesquisas em Psicologia é licenciado sob uma Licença Creative Commons Atribuição-Não Comercial 3.0 Não Adaptada. 